\title{
Clinical Outcomes And Cost-Effectiveness Of Different Staplers For Lung Lobectomy With Video-Assisted Thoracic Surgery
}

This article was published in the following Dove Press journal: Cancer Management and Research

\section{Xiaoxiong Xiao \\ Ruimin Chang \\ Yang Gao}

Thoracic Surgery Department, Xiangya Hospital Central South University, Changsha 410008, Hunan, People's Republic of China
Correspondence: Yang Gao Thoracic Surgery Department, Xiangya Hospital Central South University, 87 Xiangya Road, Changsha, Hunan 410008,

People's Republic of China

Tel +86-13973171096

Email dr.gao@csu.edu.cn
Purpose: The aim of this study was to compare intra-operative adverse events (AE), postoperative outcomes, and costs of three different types of Echelon staplers (manual activated SC45A and electrical power-activated PSE45A \& PSEE60A) used during video-assisted thoracic surgery (VATS) for lung lobectomy.

Patients and methods: We carried out a retrospective chart review of patients undergoing VATS lobectomies using one of three staplers (SC45A, PSE45A, or PSEE60A) during a 2year period at our institution. We compared intra-operative AEs, post-operative outcomes (drainage volume, chest tube duration, prolonged air leaks [PALs]), endoscopic product costs [ECs], and hospitalization costs [HCs]) amongst the three stapler groups.

Results: In all 204 peripheral lung cancer patients were included in the study (95 in the SC45A group, 72 in the PSE45A group, and 37 in the PSEE60A group). We observed intraoperative AEs in 6 patients of the SC45A group, in 4 of the PSE45A group, and in 1 of the PSEE60A group $(\mathrm{P}>0.05)$. Drainage volumes among the three groups were similar. The mean chest tube duration was shorter]st in the PSE45A group followed by those in the PSEE60A and SC45A groups $(\mathrm{P}<0.05)$. PALs were lowest in the PSE45A group and highest in the SC45A group $(\mathrm{P}<0.05)$. The mean $\mathrm{EC}$ in the PSEE60A group was significantly higher than those in the other two groups $(\mathrm{P}<0.05)$. We found no statistically significant differences in terms of HCs among groups.

Conclusion: The three endoscopic staplers had similar incidences of intra-operative AEs when used for lobectomy with VATS. Use of the PSE45A stapler was associated with the shortest chest tube duration and least PALs, while use of the PSEE60A resulted in the highest EC rate.

Keywords: VATS, hospitalization costs, HCs, prolonged pulmonary air leaks, PALs, endoscopic product costs, ECs

\section{Introduction}

Lung cancer (mostly non-small cell lung cancer [NSCLC]) is a leading cause of cancer mortality in both the United States and in China. ${ }^{1,2}$ Surgical resection is the main treatment for early-stage NSCLC and can be performed by thoracotomy, video-assisted thoracic surgery (VATS), or robotic approaches. The VATS approach has advantages like a shorter operation duration requiring a chest tube, fewer complications, less postoperative pain, and similar clinical results for tumor eradication than traditional thoracotomy. ${ }^{3,4}$ A prolonged air leak (PAL) is the most common complication after partial lung resection; risk factors include male sex, 
preoperative pulmonary dysfunction (e.g. COPD), pleural adhesions, and a poorly developed fissure. ${ }^{5,6}$ As part of the tumor resection operation, the vessels and/or bronchus need be ligated, but the association between PAL development and the type of endoscopic stapler used has not been investigated. Although endo staplers are commonly used in VATS, few data have shown how the various types of stapling devices are used (articulation, cartridge selection, usability), their costs, and their effects on both intraoperative and postoperative outcomes. Endoscopic linear stapling devices that both cut and saw are one of the more skill-demanding technics in complete video-assisted thoracoscopic lobectomy. ${ }^{7}$ Based on their activation mode, the endo staplers can be divided into two types: manual (e.g. Ethicon SC45A) and electrical power-controlled activated (e.g. Ethicon PSE45A and the PSEE60A staplers). These staplers differ in price, mechanism of action and ergonomics. The cost-effect evaluation of these type of staples is important as the healthcare community strives to provide the best care possible. ${ }^{8}$ The purpose of this investigation was to compare intra-operative adverse events (AEs), post-operative outcomes, and costs of three different types of Echelon staplers used during videoassisted thoracic surgery (VATS) for lung lobectomy.

\section{Materials And Methods}

A single surgeon at our institution performed all operations using one of three different types of Echelon Flex TM Powered ENDOPATH ${ }^{\circledR}$ Staplers (Ethicon, Cincinnati, $\mathrm{OH})$ along with compatible cartridges from Echelon: SC45A, PSE45A and PSEE60A (stapler characteristics are listed on Table 1 and Figure 2). The SC45A uses manual activation while the other two staplers (PSE45A and PSEE60A) are electrical power activated. We considered all patients from the thoracic department of Xiangya Hospital from January 2016 to December 2017 for study inclusion, and we retrospectively reviewed their data. The ethics committee of Xiangya Hospital, Central South University approved the study protocol (approval number: 2017121149). We performed all procedures in accordance with the ethical standards of the institutional and/or national research committee and with the 1964 Helsinki Declaration and its later amendments. We obtained Informed consents from all participants included in the study.

The inclusion criteria included: age $>18$ years, Eastern Cooperative Oncology Group (ECOG) status 0-1, American Society of Anesthesiologists (ASA) physical status classification $\leq 3$, lack of prior lung surgery, diagnosis of peripheral lung cancer, absence of pleural atresia, and lung lobectomy completed under VATS. We excluded patients if they had had central lung cancer, pregnancy, robotic assistance (or a staple line buttress), severe alveolar leakage in patients with treated pleural adhesions, systemic steroids administration within 30 days prior to surgery, or chemotherapy/radiation for lung cancer prior to the surgery.

The surgeon performed the radical lung cancer resections using a video thoracoscope without rib spreading. The surgical indications were those of the national comprehensive cancer network (NCCN) Clinical Practice Guidelines in Oncology for non-small cell lung cancer (version 2.2018). All surgical procedures were limited to a single lobe; and we excluded diagnostic VATS wedge resections that immediately preceded VATS lobectomies. The surgeon usually used two chest tubes after superior pulmonary lobectomy and a single chest tube after middle and lower pulmonary lobectomies. After each surgery's completion, the surgeon placed one chest tube through the camera portal to help evacuate fluid and air from the pleural cavity, and then a second chest tube through the operator portal in upper lobectomy cases. Chest X-rays were performed two days after the operation. In order to assess for pulmonary air leak, the amount of drainage was recorded, and patients were instructed to cough forcefully 3-5 times; an air leak was considered positive if bubbling in the water was observed during patient coughing. PALs were identified if air leaks were observed for more than 5 post-operative days. ${ }^{9}$ The chest tube removal indications were: 1 . Chest tube drainage $<100 \mathrm{~mL} / \mathrm{d}$. 2. Chest X-ray

Table I Characteristics Of The Three Staplers

\begin{tabular}{|l|l|l|l|l|l|}
\hline Endoscopic Stapler & Shaft Length $(\mathbf{m m})$ & Nail Numbers & Activation Mode & Twist Angle & Stapler Rows \\
\hline SC45A & 340 & 70 & Manual & $-45^{\circ}-45^{\circ}$ & 6 \\
PSE45A & 340 & 70 & Electric & $-45^{\circ}-45^{\circ}$ & 6 \\
PSEE60A & 340 & 88 & Electric & $-45^{\circ}-45^{\circ}$ & 6 \\
\hline
\end{tabular}

Abbreviation: $\mathrm{mm}$, millimeter. 
showing no gas or fluid. 3. PALs absence. Patients with PAL were managed as appropriate, and data were recorded until PAL resolution.

We retrieved data regarding patient characteristics for each stapler group including patient age, gender, BMI, smoke index, pulmonary disease history, tumor stage, tumor location, and predicted FEV1\%. We collected intra-operative data from the surgical records including operation times, blood loss, staplers and cartridge selection for ligation/transection of major vessels, bronchus and lung parenchyma; and intra-operative adverse effects. Post-operative data included chest tube duration, reasons for prolonged chest tube duration, PALs, and drainage volumes. We compared endoscopic product costs (EC) (including stapler and cartridge costs) (Table 2), and hospitalization costs (HCs) among the three stapler groups. We normalized the unit costs to US dollars (USD).

We performed the statistical analysis using the SPSS Statistics software, version 21 (IBM, Armonk, NY). We analyzed categorical data using the Chi-square test and Fisher's exact test. Continuous data was compared using one-way ANOVA (Analysis of variance) followed by Tukey's HSD (honestly significant difference test). We defined significance as $\mathrm{P}<0.05$.

\section{Results}

A total of 204 peripheral lung cancer patients (all Asian; 138 men [67.6\%] and 66 women [32.4\%], with a mean [SD] age of 58.3 [8.3]) met the inclusion criteria; the SC45A stapler was used in $95(46.6 \%)$ patients, the PSE45A stapler in 72 (35.3\%), and the PSEE60A stapler in $37(18.1 \%)$ with matching cartridges. The study cohort included $54.8 \%$ of patients who were smokers. Table 3 lists all patient demographics. Of the 204 patients diagnosed with peripheral NSCLC, 166 had TMN stages I or II (81.4\%) according to the American Joint Committee on Cancer (AJCC) tumor/node/metastasis (TNM) classification and anatomic stage/prognostic grouping for NSCLC. The patients' percent predicted FEV1 scores averaged $80.4 \%$. The mean (SD) BMI of patients was 23.3 (2.7) $\mathrm{kg} / \mathrm{m}^{2}$. Sixty-five patients had a medical history of pulmonary disease (20 cases of emphysema, 30 COPD, and 15 former tuberculosis patients). We found no statistical differences $(\mathrm{P}>0.05)$ among the stapler groups regarding gender, BMI, predicted FEV1\%, pulmonary disease histories, tumor stages or locations.

Table 4 details the operative and cost details of the three groups. The mean (SD) time for lobectomies with lymphadenectomies with VATS was $3.12(0.61)$ hours. The mean blood loss was $61.6 \mathrm{~mL}$ (range, 10 to $2000 \mathrm{~mL}$ ). The mean (SD) cartridges used during the operations were 6.68 (2.27); with 3.58 (1.87) blue cartridges and 2.11 (1.07) white cartridges. We found a statistically significant difference in white cartridge uses between the three groups. The number of white cartridges in the PSEE45A group was significantly lower than those in the other groups $(\mathrm{p}<0.05)$. The white cartridges were used for all but three (1.4\%) artery transections, and they were used for all pulmonary vein transections. With the continuous advancement of surgical techniques and improvements of surgical instruments, some of the smaller blood vessels were treated with the Hemo-lock clip, thereby decreasing the use of white cartridges. The green cartridges were used for all bronchus transections, and the blue cartridges were most frequently used for pulmonary parenchyma transections.

The EC mean (SD) for the stapler groups were $\$ 3393$ (834) for SC45A, \$3295 (712) for PSE45A, and $\$ 4865$ (1087) for PSEE60A group. The mean EC of the PSEE60A group was significantly higher than those of the other two groups $(\mathrm{P}<0.05$; Table 4$)$. We found no statistically significant differences in the patient's HCs among the three groups.

In our study cohort a total of 1372 stapling's were performed, and 11 AEs $(0.80 \%)$ occurred intraoperatively that were judged to be directly related to the staplings (Table 5). We found no statistical difference $(\mathrm{P}>0.05)$ regarding the incidence of intraoperative AEs among the three stapler groups. Of the 11 intraoperative AEs, 3 cases required stapler use ceasing while using electrically powered activated staplers. In one case, the stapler use had to

Table 2 Unit Cost Of Each Stapler And Their Matching Cartridges

\begin{tabular}{|l|l|l|l|l|l|l|}
\hline & \multicolumn{2}{|l}{ SC45A } & \multicolumn{2}{l|}{ PSE45A } & \multicolumn{2}{l|}{ PSEE60A } \\
\cline { 2 - 7 } & Stapler & Cartridge & Stapler & Cartridge & Stapler & Cartridge \\
\hline Price $(\$)$ & 707.2 & 381.3 & 1005.6 & 361.5 & 1022.1 & 592.4 \\
\hline
\end{tabular}

Abbreviation: $\$$, US dollars. 
Table 3 Patients Demographics

\begin{tabular}{|c|c|c|c|c|c|c|}
\hline & & Population (n) & SC45A & PSE45A & PSEE60A & *P-value \\
\hline \multicolumn{2}{|l|}{ Number of patients } & 204 & 95 & 72 & 37 & - \\
\hline \multicolumn{2}{|l|}{ Age (mean, SD) } & $58.3,8.3$ & $58.0,8.6$ & $58.1,8.5$ & $59.3,7.3$ & 0.71 \\
\hline \multicolumn{2}{|l|}{ Age Range } & $30-75$ & $30-74$ & $4 I-75$ & $40-72$ & - \\
\hline \multicolumn{2}{|l|}{ Male (n, \%) } & $138,67.6 \%$ & $66,69.5 \%$ & $46,63.9 \%$ & $26,70.3 \%$ & 0.69 \\
\hline \multicolumn{2}{|c|}{ Female $(\mathrm{n}, \%)$} & $66,32.4 \%$ & $29,30.5 \%$ & $26,36.1 \%$ & II, 29.7\% & \\
\hline \multicolumn{2}{|c|}{ Mean of BMI $\left(\mathrm{kg} / \mathrm{m}^{2}\right)$, SD } & $23.3,2.7$ & $23.5,2.5$ & $23.0,2.7$ & $23.2,3.5$ & 0.51 \\
\hline \multicolumn{2}{|c|}{ Mean predicted FEVI\%, SD } & $80.4,21.3$ & $81.3,20.7$ & $78.8,23.8$ & $80.3,22.6$ & 0.77 \\
\hline \multicolumn{2}{|c|}{ Range of FEVI } & $58-180$ & $60-158$ & $58-160$ & $65-180$ & - \\
\hline \multicolumn{2}{|l|}{ Emphysema } & 20 & 9 & 7 & 4 & 0.95 \\
\hline \multicolumn{2}{|l|}{ COPD } & 30 & 13 & 10 & 7 & \\
\hline \multicolumn{2}{|l|}{ Tuberculosis } & 15 & 7 & 6 & 2 & \\
\hline \multirow[t]{6}{*}{ Tumor stage } & IA & 85 & 31 & 38 & 16 & 0.17 \\
\hline & IB & 14 & 8 & 6 & 0 & \\
\hline & IIA & 28 & 18 & 8 & 2 & \\
\hline & IIB & 39 & 17 & 14 & 8 & \\
\hline & IIIA & 36 & 19 & 6 & 11 & \\
\hline & IIIB & 2 & 2 & 0 & 0 & \\
\hline \multirow[t]{5}{*}{ Tumor lobe location } & Right upper & 59 & 25 & 22 & 12 & 0.76 \\
\hline & Right middle & 9 & 4 & 2 & 3 & \\
\hline & Right low & 52 & 24 & 18 & 10 & \\
\hline & Left upper & 68 & 36 & 24 & 8 & \\
\hline & Left low & 16 & 6 & 6 & 4 & \\
\hline
\end{tabular}

Notes: *Analysis by one-way ANOVA and Chi square test.

Abbreviations: SD, standard deviation; $\mathrm{n}$, number; BMI, body mass index; kg, kilograms; m, meter; FEV forced expiratory volume; COPD, chronic obstructive pulmonary disease.

be stopped after encountering a severe lymph node calcification adjacent to an incomplete developed pulmonary fissure; the surgeon managed this by releasing the activation button and switching from forward to reverse mode, and then inserting a new carton cartridge, re-applying the stapler, and cutting and suturing. Intraoperative leakages were noted during two operations (one performed with the SC45A and one with the PSE45A staplers) due to the presence of thick pulmonary parenchyma. The surgeon used a 4-0 prolene suture to reinforce the parenchymabased transection edges to manage these cases. One patient in the SC45A stapler group and one in the PSE45A stapler group had blood oozing after pulmonary vein cutting and stapling while using the white cartridge. In those cases, the surgeon suggested that tissue fragility and stapler-tissue thickness mismatches were probably to blame; this was managed by adding an extra hemo-lock on the proximal end of the pulmonary vein. One patient in the SC45A group sustained a pulmonary artery injury while the surgeon was using the stapler to cut and staple the artery. In this case, while attempting to twist the white cartridge for a better angle, the distance from the artery and stapler joint was not long enough and the pulmonary artery was injured leading to catastrophic bleeding $(2000 \mathrm{~mL})$; the surgeon repaired the artery with a 4-0 prolene suture. We found no statistical difference between the three stapler groups in terms of estimated blood losses.

Table 6 presents the postoperative outcomes. We found a statistically significant difference in duration of chest tubes between the three groups. The PSE45A group had the shortest chest tube duration (mean 4.4 days), followed by the PSEE60A group (mean 6.5 days), and the SC45 group (10.0 days) $(\mathrm{p}<0.05)$. Reasons for prolonged chest tube durations included PALs (31,15.2\%), chylothorax $(2,0.9 \%)$, reoperation $(1,0.5 \%)$, and excessive drainage volume (drainage $\geq 100 \mathrm{~mL} / \mathrm{d}$ five days after operation [45.22.1\%]). PALs led to prolonged chest tube durations. The incidence of PALs was significantly higher in the SC45A group (25.3\%) followed by that in the PSE45A group (5.6\%), and that in the PSEE60A group (8.1\%). We found no significant differences in terms of postoperative drainage amongst the three stapler groups. Figure 1 presents the flow chart for the management of patients with PALs. 
Table 4 Operative And Cost Details

\begin{tabular}{|c|c|c|c|c|c|c|}
\hline & & Overall & SC45A & PSE45A & PSEE60A & *P-value \\
\hline \multicolumn{2}{|l|}{ Patients } & 204 & 95 & 72 & 37 & - \\
\hline \multicolumn{2}{|c|}{ Mean of operative time in hours } & $3.12(0.61)$ & $3.14(0.64)$ & $3.12(0.63)$ & $3.07(0.5 \mathrm{I})$ & $\begin{array}{l}{ }^{\mathrm{a}} 0.97 \\
\mathrm{~b} 0.82 \\
{ }^{\mathrm{c}} 0.91\end{array}$ \\
\hline \multicolumn{2}{|c|}{ Mean of estimated blood loss in $\mathrm{mL}$} & $61.6(180.7)$ & $82.4(259.0)$ & $37.6(36.3)$ & $54.9(63.2)$ & $\begin{array}{l}{ }^{\mathrm{a}} 0.25 \\
{ }^{\mathrm{b}} 0.71 \\
{ }^{\mathrm{c}} 0.88\end{array}$ \\
\hline \multirow[t]{3}{*}{ Cartridge Use (firings) } & Total & $6.68(2.27)$ & $6.94(2.52)$ & $6.33(2.03)$ & $6.73(2.04)$ & $\begin{array}{l}{ }^{\mathrm{a}} 0.20 \\
\mathrm{~b} 0.88 \\
{ }^{\mathrm{c}} 0.66\end{array}$ \\
\hline & Blue & $3.58(1.87)$ & $3.54(1.88)$ & $3.66(2.06)$ & $3.52(1.5 \mathrm{I})$ & $\begin{array}{l}\text { a } 0.91 \\
\text { b } 0.99 \\
{ }^{c} 0.92\end{array}$ \\
\hline & White & $2.11(1.07)$ & $2.40(0.93)$ & $1.67(0.95)$ & $2.21(1.34)$ & $\begin{array}{l}\mathrm{a}^{\mathrm{a}}<0.00 \mathrm{I} \\
\mathrm{b} 0.60 \\
{ }^{\mathrm{c}} 0.02\end{array}$ \\
\hline \multicolumn{2}{|l|}{ Mean EC in $\$$} & $3625(1026)$ & $3392(834)$ & $3295(7 \mid 2)$ & $4865(1087)$ & $\begin{array}{l}{ }^{\mathrm{a}} 0.74 \\
{ }^{\mathrm{b}}<0.00 \mathrm{I} \\
{ }^{\mathrm{c}}<0.00 \mathrm{I}\end{array}$ \\
\hline \multicolumn{2}{|l|}{ Mean $\mathrm{HC}$ in $\$$} & $10,803(1590)$ & $10,648(1896)$ & $10,890(1256)$ & II,038 (I245) & $\begin{array}{l}{ }^{\mathrm{a}} 0.59 \\
\mathrm{~b} 0.4 \mathrm{I} \\
{ }^{\mathrm{c}} 0.88\end{array}$ \\
\hline
\end{tabular}

Notes: Data expressed as Mean (Standard Deviation). *Intergroup differences analysed by one-way ANOVA followed by Tukey's HSD. a'SC45A vs PSE45A; 'SC45A vs PSEE60A; ' ${ }^{\text {PSE } 45 A ~ v s ~ P S E E 60 A . ~}$

Abbreviations: \$, US dollars; $\mathrm{mL}$, millilitres; $\mathrm{EC}$, endoscopic product costs; $\mathrm{HC}$, hospitalization costs; ANOVA, analysis of variance; HSD, honestly significant difference test.

Since blue cartridges were frequently used for pulmonary parenchyma transections, we compared the number of blue cartridges used amongst patients with and without PALs. We found no significant differences in the number of blue cartridges used between patients with and without PALs in the SC45A and PSEE60A stapler groups, but the patients in the PSE45A group $(\mathrm{P}<0.05)$ required less blue cartridges for their PALs as compared to non-PAL patients (Table 7).

\section{Discussion}

The use of VATS for lung cancer management has increased worldwide due to lower patient morbidity and similar oncologic outcomes as compared to open surgery. ${ }^{10}$ With the

Table 5 Intraoperative Adverse Effects Per Group

\begin{tabular}{|l|l|l|l|l|l|l|}
\hline \multirow{2}{*}{ Locations } & Types Of AEs & \multicolumn{2}{|l|}{ Numbers } & PSE-value \\
\cline { 3 - 7 } & & Total & SC45A(95) & PSE45A(72) & PSEE60A(37) \\
\hline PA & Catastrophic bleeding & I & I & 0 & 0 & 0.84 \\
\hline PV & Oozing & 2 & I & I & 0 \\
\hline PB & Leakage & 2 & 2 & 0 & 0 & 0 \\
\hline PP & Leakage & 3 & 2 & 1 & 1 \\
\hline
\end{tabular}

Notes: *Fishers exact test for overall incidence of adverse events.

Abbreviations: AE, Adverse events; PA, pulmonary artery; PV, pulmonary vein; PB, pulmonary bronchus; PP, pulmonary parenchyma. 
Table 6 Postoperative Data

\begin{tabular}{|c|c|c|c|c|c|c|}
\hline & & Overall & SC45A & PSE45A & PSEE60A & $P$-value \\
\hline \multicolumn{2}{|l|}{ Number of patients } & 204 & 95 & 72 & 37 & - \\
\hline \multicolumn{2}{|c|}{ Mean of chest tube duration (days), SD* } & $7.74,5.85$ & $10.00,5.10$ & $4.39,1.84$ & $6.5 \mathrm{I}, 2.17$ & ${ }^{a}<0.00001$ \\
\hline \multirow[t]{5}{*}{ Days of chest tube duration } & $\leq 5$ & 132 & 49 & 58 & 25 & ${ }^{\#} 0.003$ \\
\hline & 6 or 7 & 33 & 14 & 10 & 9 & \\
\hline & $>7, \leq 10$ & 15 & 13 & 2 & 0 & \\
\hline & $>10, \leq 13$ & 14 & 10 & 2 & 2 & \\
\hline & $>13$ & 10 & 9 & 0 & 1 & \\
\hline \multicolumn{2}{|l|}{ Prolong tube duration (n, \%) } & $72,35.2 \%$ & $46,48.4 \%$ & $14,19.4 \%$ & $12,32.4 \%$ & ${ }^{\#} 0.0004$ \\
\hline \multicolumn{2}{|l|}{ Prolonged air leaks (n, \%) } & $31,15.2 \%$ & $24,25.3 \%$ & $4,5.6 \%$ & $3,8.1 \%$ & ${ }^{\#} 0.0008$ \\
\hline \multicolumn{2}{|l|}{ Chylothorax (n, \%) } & $2,0.9 \%$ & $2,2.1 \%$ & 0 & 0 & - \\
\hline \multicolumn{2}{|l|}{ Reoperation (n, \%) } & $\mathrm{I}, 0.5 \%$ & 0 & $\mathrm{I}, \mathrm{I} .4 \%$ & 0 & - \\
\hline \multicolumn{2}{|c|}{ Excessive drainage volume (n, \%) } & $45,22.1 \%$ & $21,22.1 \%$ & $13,18.1 \%$ & II, $29.7 \%$ & - \\
\hline \multirow{3}{*}{\multicolumn{2}{|c|}{ Mean of postoperative drainage volume $(\mathrm{mL}), \mathrm{SD} *$}} & 243,182 & $250.9,238.7$ & $216.6,50.7$ & $274.6,175.3$ & ${ }^{\mathrm{a}} 0.45$ \\
\hline & & & & & & ${ }^{b} 0.77$ \\
\hline & & & & & & ${ }^{c} 0.25$ \\
\hline
\end{tabular}

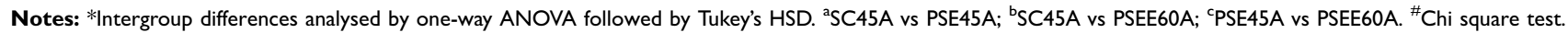
Abbreviations: SD, standard deviation; $n$, number; $\mathrm{mL}$, millilitres; ANOVA, analysis of variance; HSD, honestly significant difference test.

development of VATS, the endoscopic tools and products to facilitate the surgical procedure have improved. The endoscopic linear cutter/staplers are widely used during VATS and they have shown to be both safe and effective. ${ }^{11}$ In this report, we retrospectively reviewed the outcomes and costs associated with 3 different types of Ethicon stapler products (SC45A, PSE45A, and PSEE60A staplers); these staplers have gone through version changes (stapler SC45A, PSE45A, and PSEE60A were introduced to China in 2011, 2016, and 2017, respectively). The staplers share similarities including their long axis, axis diameter, opening angle, twist angle, and stapler rows. In our practice, we have noted problems with these endoscopic products including issues with the cartridge to joint length being too long (especially in small patients) that can result in incision impediments when ligating and stapling the arteries and veins. These limitations in the staplers have led to AEs including reports of active bleeding after surgery using the endoscopic suture. ${ }^{12} \mathrm{We}$ compared three endoscopic staplers for this investigation and found no significant differences between them regarding intra-operative AEs, and they all appeared to be safe and effective during VATS for lung lobectomies.

PALs is one of the most common postoperative complication in patients that have undergone VAT pulmonary resections and is a main factor leading to prolonged hospitalizations; ${ }^{13}$ the PAL incidence has been reported to be $6-15 \%$ after lobectomy surgeries. ${ }^{14,15}$ PAL risk factors include male sex, ${ }^{16}$ preoperative pulmonary dysfunction, presence of pleural adhesions, and poorly developed fissures; whether an association exists between the PALs and the endoscopic stapler used is unclear.

In this investigation, the prevalence of PALs in PSE45A and PSEE60A groups were significantly lower than that of the SC45A group $(\mathrm{P}<0.05)$. Compared to the manually activated staplers (e.g. SC45A), the electrically powered ones (e.g. PSE45A and PSEE60A staplers) appear more stable and produce a more uniform force on the parenchyma during staple deployment. Our results did show a higher rate of PALs with the manual activated stapler (SC45A stapler) than with the electrically activated staplers (e.g. PSE45A and PSEE60A staplers); this PAL incidence reduction also translated into reduced mean chest tube duration for those groups of patients. We found no statistical differences $(\mathrm{P}>0.05)$ in terms of the incidence of PALs and chest tube duration between the electrically activated stapler groups (PSE45A and PSEE60A). We found a reduced PAL rate trend in the PSE45A stapler group (5.6\%) as compared to the PAL incidence trend in the PSEE60A stapler group (8.1\%). This difference may be due to the compression and fixation of the PSEE60A stapler being stronger and restricting the re-expansion of the pulmonary tissue, resulting in 


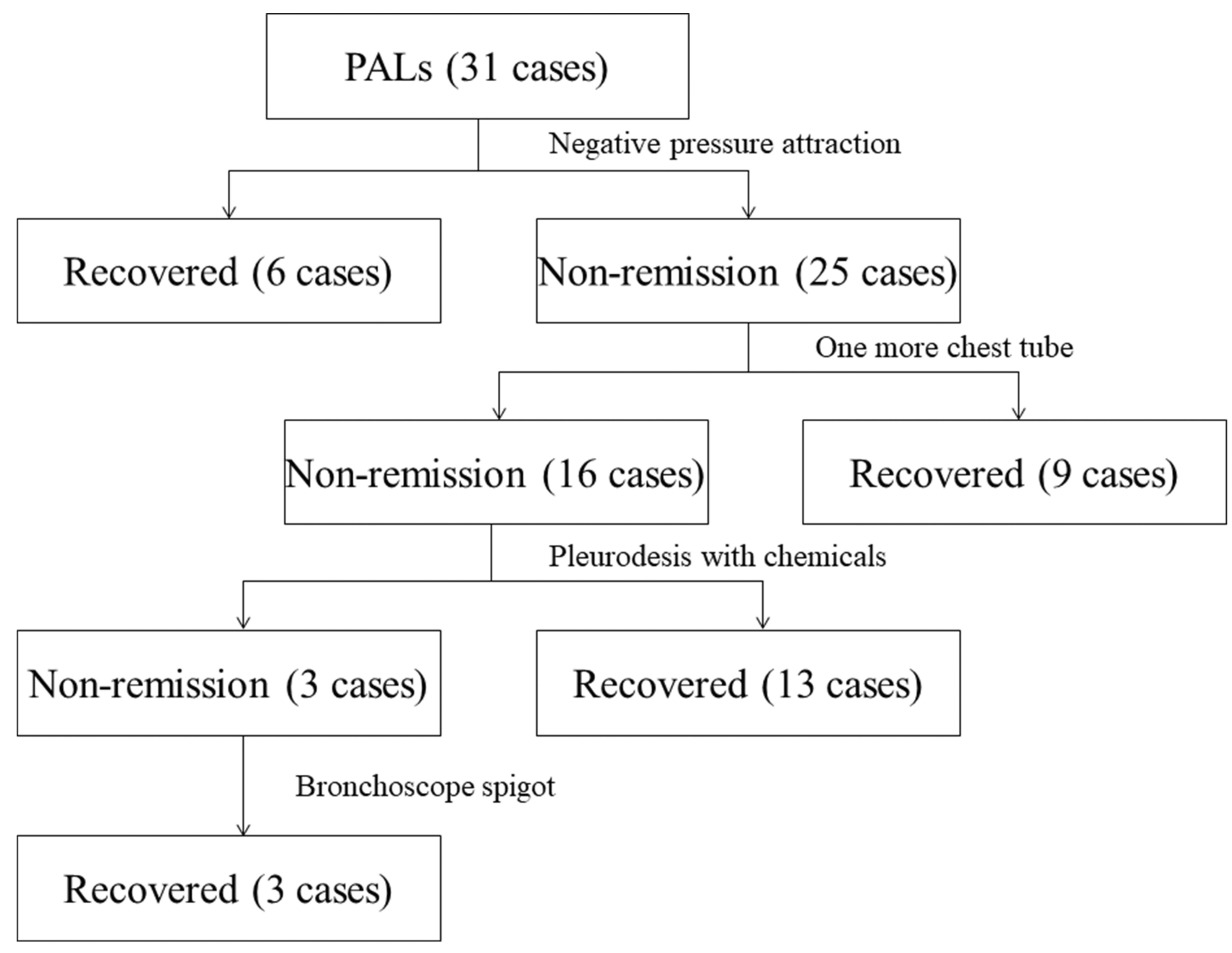

Figure I Flow chart of postoperative prolonged pulmonary air leaks treatment protocol in our patients.

tearing of the pulmonary parenchyma and in an alveolarpleural fistula. However, we did not perform digital assessments of PAL and are aware of this study limitation. The association between the numbers of blue cartridges used and the PAL incidence was inverse; the number of blue cartridges used in patients with PALs was lower than that used in patients with PALs. The use of less blue cartridges was common for patients with thin and short pulmonary parenchymas; we think in these cases the closed height of the nail staples from the blue cartridges may be too high and the cutting and nail suturing of the lung parenchyma may not be done with sufficient close apposition predisposing the patients to development of alveolar fistulas after surgery when the area is stressed by patient coughing. Our results suggest the following recommendations when using the staplers: 1 . The surgeon should choose the appropriate closed suture height (cartridge) during VATS, especially when addressing thick pulmonary parenchyma (as is common in patients with a history of pulmonary tuberculosis due to adhesions and parenchymal thickening) (21) or thin pulmonary parenchyma (in patients with a thin fissure). 2. The surgeon should minimize the overlap of two cartridges when using the stapler to avoid poor quality of the suture line. 3. The surgeon should add an extra suture by hand in cases with severe lymph node calcifications in close proximity to the pulmonary parenchyma or bronchus.

A cost-effective healthcare is important worldwide; according to the latest medical reform in China, a case of thoracoscopic lung cancer radical resection should cost less than $\$ 8375$. Most of the unit costs derived from the Publicity Medicine Prices of Hunan (http://www.hnyyjg. com/a/jiagexinxi/yiyaoxinxi/shengjiyiliaofuwujiage/2018/ 0425/362.html) based on data collected from all the hospitals in the Hunan province of China. From the patients enrolled in this study over a 2-year period, the mean ECs 


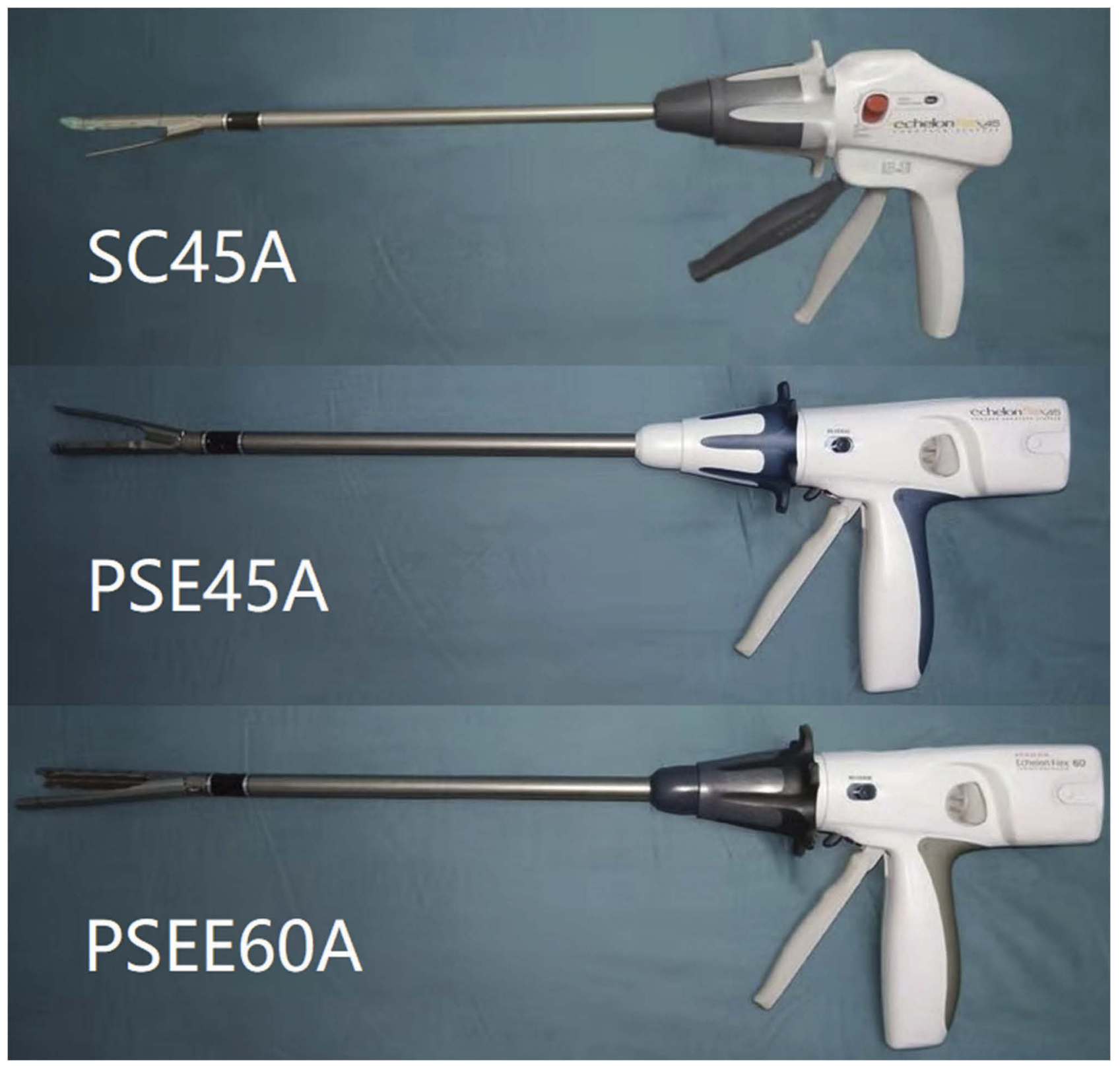

Figure 2 Images of staplers used in the study: SC45A, PSE45A and PSEE60A.

and the HCs were $\$ 3625$ and $\$ 10,177$, respectively. Of the endoscopic products used, the PSEE60A (\$4865) stapler

Table 7 Blue Cartridges Used In Patients With And Without Prolonged Air Leaks

\begin{tabular}{|l|l|l|l|}
\hline \multirow{2}{*}{} & \multicolumn{3}{|l|}{ Number Of Blue Cartridges (Mean, SD) } \\
\cline { 2 - 4 } & SC45A & PSE45A & PSEE60A \\
\hline PALs group & $3.5,1.7$ & $2.0,0.6$ & $2.7,0.6$ \\
No-PALs group & $3.7,1.9$ & $3.7,2.0$ & $3.6,1.6$ \\
P-value & 0.62 & 0.01 & 0.08 \\
\hline
\end{tabular}

Abbreviations: PAL, prolonged air leak; SD, standard deviation. group had the highest mean EC while the PSE45A group had the lowest mean EC (\$3295). The main reasons for the different cost of these staplers include the cartridge costs and the number of cartridges used in each case. The price of the PSEE60A stapler and its cartridges are higher than those of the other two staplers; but even though the PSE45A stapler and its cartridges cost more than the SC45A stapler and its cartridges, our patients in the PSE45A group required fewer cartridges (mean number of cartridges, 7.0 in the SC45A group and 6.3 in the PSE45A; $\mathrm{p}<0.05$ ). This probably resulted in the low EC for the PSE45A group in our study. 


\section{Conclusion}

In conclusion, the three endoscopic staplers used in this investigation had similar incidences of intra-operative AEs. The electrical-powered activation stapler groups (PSE45A and PSEE60A) had a significantly shorter chest tube duration and lower incidence of PALs compared to the manual activation stapler group (SC45A). The PSE45A stapler had the shortest chest tube duration and lowest incidence of PALs. The PSEE60A stapler was found to be the costliest of the 3 staplers studied.

\section{Funding}

This work was supported by the National Natural Science Foundation of China (81401901, 81372515 and 81602027), and from the Key Research and Development Program of Hunan Province (No.2016JC2039).

\section{Disclosure}

The authors report no proprietary or commercial interest in any product mentioned or concept discussed in this article.

\section{References}

1. Miller KD, Siegel RL, Lin CC, et al. Cancer treatment and survivorship statistics, 2016. CA Cancer J Clin. 2016;66(4):271-289. doi:10.3322/ caac. 21349

2. Chen W, Zheng R, Baade PD, et al. Cancer statistics in China, 2015. CA Cancer J Clin. 2016;66(2):115-132. doi:10.3322/caac.21338

3. Cao C, Manganas C, Ang SC, Yan TD. A meta-analysis of unmatched and matched patients comparing video-assisted thoracoscopic lobectomy and conventional open lobectomy. Ann Cardiothorac Surg. 2012;1 (1):16-23. doi:10.3978/j.issn.2225-319X.2012.04.18

4. Liu Y, Gao Y, Zhang H, et al. Video-assisted versus conventional thoracotomy pneumonectomy: a comparison of perioperative outcomes and short-term measures of convalescence. J Thorac Dis. 2016;8(12):3537-3542. doi:10.21037/jtd.2016.12.24
5. Attaar A, Winger DG, Luketich JD, et al. A clinical prediction model for prolonged air leak after pulmonary resection. J Thorac Cardiovasc Surg. 2017;153(3):690-699.e2. doi:10.1016/j.jtcvs.2016.10.003

6. Pan H, Chang R, Zhou Y, Gao Y, Cheng Y, Zhang C. Risk factors associated with prolonged air leak after video-assisted thoracic surgery pulmonary resection: a predictive model and meta-analysis. Ann Transl Med. 2019;7(5):103. doi:10.21037/atm.2019.02.17

7. Jeon YJ, Choi YS, Lee KJ, Lee SH, Pyo H, Choi JY. Outcomes of pulmonary resection and mediastinal node dissection by video-assisted thoracoscopic surgery following neoadjuvant chemoradiation therapy for stage IIIA N2 non-small cell lung cancer. Korean J Thorac Cardiovasc Surg. 2018;51(1):29-34. doi:10.5090/kjtcs.2018.51.1.29

8. Zeng X, Karnon J, Wang S, Wu B, Wan X, Peng L. The cost of treating advanced non-small cell lung cancer: estimates from the chinese experience. PLoS One. 2012;7(10):e48323. doi:10.1371/journal.pone.0048323

9. Licht PB, Ribaric G, Crabtree T, et al. Prospective Clinical Study to Evaluate Clinical Performance of a Powered Surgical Stapler in Video-assisted Thoracoscopic Lung Resections. Surg Technol Int. 2015;27:67-75.

10. Vannucci F, Gonzalez-Rivas D. Is VATS lobectomy standard of care for operable non-small cell lung cancer? Lung Cancer. 2016;100:114119. doi:10.1016/j.lungcan.2016.08.004

11. Chekan E, Whelan RL. Surgical stapling device-tissue interactions: what surgeons need to know to improve patient outcomes. Med Devices (Auckl). 2014;7:305-318. doi:10.2147/MDER.S67338

12. Dugan KC, Laxmanan B, Murgu S, Hogarth DK. Management of persistent air leaks. Chest. 2017;152(2):417-423. doi:10.1016/j. chest.2017.02.020

13. Yoo A, Ghosh SK, Danker W, Kassis E, Kalsekar I. Burden of air leak complications in thoracic surgery estimated using a national hospital billing database. Clinicoecon Outcomes Res. 2017;9:373383. doi:10.2147/CEOR.S133830

14. Boffa DJ, Dhamija A, Kosinski AS, et al. Fewer complications result from a video-assisted approach to anatomic resection of clinical stage I lung cancer. J Thorac Cardiovasc Surg. 2014;148(2):637-643. doi:10.1 016/j.jtcvs.2013.12.045

15. Burt BM, Shrager JB. The prevention and management of air leaks following pulmonary resection. Thorac Surg Clin. 2015;25(4):411419. doi:10.1016/j.thorsurg.2015.07.002

16. Orsini B, Baste JM, Gossot D, et al. Index of prolonged air leak score validation in case of video-assisted thoracoscopic surgery anatomical lung resection: results of a nationwide study based on the French national thoracic database, EPITHOR. Eur J Cardiothorac Surg. 2015;48(4):608-611. doi:10.1093/ejcts/ezu505

\section{Publish your work in this journal}

Cancer Management and Research is an international, peer-reviewed open access journal focusing on cancer research and the optimal use of preventative and integrated treatment interventions to achieve improved outcomes, enhanced survival and quality of life for the cancer patient.
The manuscript management system is completely online and includes a very quick and fair peer-review system, which is all easy to use. Visit http://www.dovepress.com/testimonials.php to read real quotes from published authors. 